\title{
Psychosocial stress and hypertension in nursing staff
}

\author{
Janete de Souza Urbanetto ${ }^{1}$, Tânia Solange Bosi de Souza Magnago², Ana Elizabeth Figueiredo *1,3, Carlos Eduardo \\ Poli-de-Figueiredo ${ }^{3}$ \\ ${ }^{1}$ Nursing School, Pontifical Catholic University of Rio Grande do Sul (PUCRS) Porto Alegre, Brazil \\ ${ }^{2}$ Nursing School, Federal University of Santa Maria, Brazil \\ ${ }^{3}$ Medicine and Health Sciences, Pontifical Catholic University of Rio Grande do Sul, Porto Alegre, Brazil
}

Received: May 18, 2015

DOI: $10.5430 /$ cns.v3n4p15
Accepted: June 17, 2015

Online Published: June 24, 2015

URL: http://dx.doi.org/10.5430/cns.v3n4p15

\begin{abstract}
Objective: To describe the prevalence of systemic arterial hypertension (SAH) and verify the association between psychosocial stress and systemic arterial hypertension in nursing staff.

Methods: A cross-sectional study conducted in an emergency care hospital in Southern Brazil. An instrument with sociodemographic, labor, clinical data and questions of Job Stress Scale was used. Descriptive and multivariate statistics analysis was performed.

Results: The prevalence of SAH was 32\%. An association was shown between SAH and being considered overweight/obese, having a larger waist circumference, age and self-reported skin color. No association was found between psychosocial stress (Demand Control Model quadrants) and systemic arterial hypertension, as well as with the different levels of blood pressure.

Conclusions: High prevalence of hypertension was found among nursing staff although psychosocial stress was not associate with its occurrence. Follow-up studies are needed to elucidate more clearly the influence of the workplace environment on the health-illness process of the workers.
\end{abstract}

Key Words: Hypertension, Psychological stress, Occupational health, Nursing

\section{INTRODUCTION}

The study of stress has been developed further in recent decades, in particular, stress related to the workplace and its consequences on the health of workers. The DemandControl Model (DCM) proposed by Karasek is a model used to evaluate psychosocial stress, correlating two psychosocial aspects of work, psychological demand and control over work, with the risk of becoming ill, the Job Stress Scale, has been validated for use in Brazil. ${ }^{[1]}$

The two dimensions evaluated in the DCM address specific aspects of the work process. The first, control over the work, encompasses aspects related to the use of intellectual abilities and decisional authority; the second, psychological demand, concerns the psychological demands faced by the worker during the performance of their tasks. ${ }^{[1,2]}$

The demand and control dimensions form the four quadrants of the DCM: high strain (high psychological demand and low control); active work (high psychological demand and high control); passive work (low psychological demand and low control) and low strain (low psychological demand and high control). ${ }^{[1,2]}$ According to the authors of the scale, workers who are in the high strain and passive work quadrants would have greater chances of becoming ill, while those in the low strain quadrant would present better conditions for preservation of health. ${ }^{[2]}$

Work-related stress has been analyzed separately or in as-

\footnotetext{
* Correspondence: Ana Elizabeth Figueiredo; Email: anaef@pucrs.br; Address: Nursing School, Av Ipiranga 6681 Partenon Porto Alegre/RS CEP: 90619-900, Brazil.
} 
sociation with health conditions, such as cardiovascular diseases, ${ }^{[2]}$ including systemic arterial hypertension (SAH),${ }^{[3-5]}$ musculoskeletal disorders ${ }^{[6]}$ and psychological problems, ${ }^{[7,8]}$ among others. The repercussions of stress can impact on the entire organism but the cardiovascular system is widely involved. ${ }^{[9]}$ Systemic arterial hypertension is described as "a multifactorial clinical condition characterized by high and sustained levels of arterial blood pressure" with high rate and low control ${ }^{[10]}$ Research has shown a Brazilian and global SAH prevalence varying from $25.5 \%$ to $37.8 \% .^{[11-13]}$

Studies using the DCM have been widely used around the world in search of evidence regarding the association between the occurrence of health alterations in workers and the high strain and/or passive work, working environment. The results found for the prediction of health risk in relation to cardiovascular alterations, and more specifically $\mathrm{SAH}$, are conflicting. ${ }^{[3,4,14,15]}$

Based on these considerations, the hypothesis of this study is that work performed under high psychological demand and low control over the work activity (high strain) is positively associated with the occurrence of systemic arterial hypertension in the evaluated workers. Therefore, the aim of this study was to describe the prevalence of SAH and verify the association between psychosocial stress and systemic arterial hypertension among the nursing staff of an emergency care hospital.

\section{METHODS}

A cross-sectional study was conducted in an emergency care of a public hospital in Southern Brazil. The population comprised of 606 nursing staff (nursing technicians/assistants) that make up the Nursing Service. A total of 185 workers were excluded for one of the listed reasons: workers with temporary contracts; working at the hospital for less than a year; being on leave (off sick, pregnancy, personal problems); workers in management positions; and those working providing indirect care to patients. Of the remaining 421 eligible workers, 388 (92.2\%) agreed to participate in the study.

Data collection was conducted from January to June 2010 using a questionnaire containing information related to sociodemographic, labor and clinical aspects, and relative to the Job Stress Scale ${ }^{[2]}$ (psychosocial stress-exposure). Anthropometric measurements (weight, height, waist and hip circumference) were taken and blood pressure checked.

Blood pressure (BP) was measured twice using the left arm positioned at heart level and with the volunteer seated with lower limbs uncrossed. The first measurement was taken after being at rest for at least ten minutes. The second BP recording was carried out after completion of the question- naire. The researcher collected data with two nurse students neither had any relationshiop with the hospital in question, during the measuments everyday clothes were used. All participants that were identified as having hypertension were refered to medical staff.

The VI Brazilian Guidelines on Hypertension ${ }^{[10]}$ were used to classify the BP. The mean of values recorded from the first and second measurements were calculated and workers considered to be hypertensive with a systolic $\mathrm{BP} \geq 140 \mathrm{mmHg}$ and/or diastolic BP $\geq 90 \mathrm{mmHg}$. Workers who self-reported a medical diagnosis of SAH and those that used antihypertensive medication were also considered to be hypertensive, regardless of the values recorded when BP measurements were taken.

Body weight was checked using a digital scale and height measured with the aid of a stadiometer. The body mass index (BMI) was calculated using the formula $\mathrm{BMI}=$ weight $/$ height $^{2}$. A BMI $\geq 25$ and $<30 \mathrm{~kg} / \mathrm{m}^{2}$ was considered as overweight and a BMI $\geq 30 \mathrm{~kg} / \mathrm{m}^{2}$ as obese. ${ }^{[16]}$

The Job Stress Scale, validated for Portuguese, was adopted for evaluation of workplace stress. ${ }^{[1]}$ As previously stated, the control over the work and psychological demand dimensions form the demand-control quadrants. Each dimension generated a score by adding the points attributed to each of the questions and was then classified as low or high, after confirmation of normal distribution through averaging. ${ }^{[1]}$ The extent of low demand ( $\leq 15$ points) or high demand ( $\geq 16$ points) was defined with an average score of 14.64 $( \pm 2.4)$. For the control dimension, the degree of low control ( $\leq 17$ points) or high control ( $\geq 18$ points) was defined by an average score of $16.88( \pm 2.3)$.

The $\mathrm{DCM}^{[1,2]}$ quadrants were defined from the combinations of psychological demand (high and low) and control over the work (high and low) and categorized as high strain work (high psychological demand and low control); active work (high psychological demand and high control); passive work (low psychological demand and low control); and low strain work (low psychological demand and high control).

Results were analyzed using the software SPSS ${ }^{\circledR}$ version 18.0 (Statistical Package to Social Sciences for WindowsChicago, IL, USA), using descriptive statistics (measures of central tendency and variability, absolute and relative distribution). Symmetry of continuous distributions was evaluated using the Kolmogorov-Smirnov test. The chi-square test or Fisher's exact test were used to evaluate the association between two qualitative variables. Continuity correction was used in situations of a $2 \times 2$ contingency table. Monte Carlo simulation was used where at least one variable had polyto- 
mous characteristics. A level of significance $(\alpha)$ of $5 \%$ was adopted.

Multivariate analysis using binary logistic regression (Enter Method) was used, adjusted for confounding factors (variables associated both to the outcome and exposure to a significance level of 0.25 ). Odds Ratio was used to measure effect and the Hosmer-Leneshow test in order to verify the best-adjusted model (closest to 1.0).

The research project was approved by the Research Ethics Committee of the Institution (Protocol $n^{\circ}$ OF.CEP-997/09) and by the Municipal Department of Health (CEP 399 Protocol $\mathrm{N}^{\circ}$ 001.044987.09.9) and each participant signed an informed consent form.

\section{RESULTS}

The nursing staff in the study sample $(n=388)$ presented a mean age of $48.3( \pm 7.2)$ years, with a minimum of 29 years and maximum of 68 years. The sample were predominantly in the 49 to 59 years $(41.8 \%)$ age group, female $(81.2 \%)$, selfreported white $(71.4 \%)$, with a high school educational level (58\%), married or living in a stable relationship (56.4\%), with children (79.4\%), and an average family income per capita of US 650 per month.

Occupational characteristics showed a predominance of nursing technicians/assistants $(85.1 \% ; n=330)$, with a mean of $15.9( \pm 6.7)$ years in the job. The area with the largest workforce was the Intensive Care Units $(39.4 \% ; n=153)$, followed by the Inpatient Units $(23.5 \% ; n=91)$, Emergency Care Units $(22.7 \%, n=88)$ and Surgical Center $(14.4 \%$; $n=56)$. More than half worked at night $(51.5 \% ; n=200)$, with 12 -hour work shifts $(75.3 \% ; n=292)$ and had no other employment $(82.9 \% ; n=322)$. The mean BMI was 27.9 $( \pm 5.4) \mathrm{kg} / \mathrm{m}^{2}$, with $37.6 \%(n=146)$ being overweight and $29.4 \%(n=114)$ obese.

A $32 \%(n=124)$ prevalence of systemic arterial hypertension was revealed. It is highlighted that at the time of data collection $38.7 \%(n=48)$ of these were found to have stage I hypertension, $6.45 \%$ had stage II, 3.2\% stage III and $11.6 \%$ $(n=45)$ were considered to have a borderline classification.

Combining the psychological demand and control over the work dimensions in order to obtain the demand-control quadrants revealed a significantly higher frequency $(p<.05)$ in the passive work $35.6 \%(n=138)$ and low strain $26.5 \%$ ( $n=103$ ) quadrants. The quadrants of active work and high strain comprised of $16.5 \%(n=64)$ and $21.4 \%(n=83)$ of professionals, respectively.

A statistically significant relationship was shown between psychosocial stress and under graduate workers $(p=.042)$ who performed their duties in the Inpatient units $(p=.04)$ and were nursing technicians/assistants $(p<.001)$. Similarly, they showed systemic arterial hypertension associated with being older than 48 years $(p<.001)$, having a self-reported skin color of non-white $(p<.001)$, being a nursing technician/assistant $(p=.009)$, having a per capita income less than US $675(p=.002)$, being overweight/obese $(p<.001)$.

Table 1 presents the relationship of occurrence or nonoccurrence of SAH and classification of the blood pressure levels with the JSS demand-control quadrants. The data shows that no association was found between psychosocial stress (DCM quadrants) and systemic arterial hypertension, as well as with the different levels of blood pressure.

Table 1. Relationship of occurrence/non-occurrence of Systemic Arterial Hypertension and classification of blood pressure levels with the Job Stress Scale demand-control quadrants

\begin{tabular}{|c|c|c|c|c|c|}
\hline Blood Pressure & Low Strain & Passive Work & Active Work & High Strain & $p$ \\
\hline \multicolumn{6}{|c|}{ Systemic Arterial Hypertension } \\
\hline No hypertension & $70(26.5)$ & $97(36.7)$ & $47(17.8)$ & $50(18.9)$ & \multirow{2}{*}{$.321^{\#}$} \\
\hline Hypertension & $33(26.6)$ & $41(33.1)$ & $17(13.7)$ & $33(26.6)$ & \\
\hline \multicolumn{6}{|c|}{ Blood pressure Classification } \\
\hline Good & $59(28.2)$ & $73(34.9)$ & $38(18.2)$ & $39(18.7)$ & \multirow{6}{*}{$.914^{\# \#}$} \\
\hline Normal & $20(27.0)$ & $27(36.5)$ & $12(16.2)$ & $15(20.3)$ & \\
\hline Borderline & $10(22.2)$ & $16(35.6)$ & $7(15.6)$ & $12(26.7)$ & \\
\hline Stage 1 hypertension ${ }^{*}$ & $10(20.8)$ & $18(37.5)$ & $5(10.4)$ & $15(31.3)$ & \\
\hline Stage 2 hypertension ${ }^{* *}$ & $2(25.0)$ & $3(37.5)$ & $1(12.5)$ & $2(25.0)$ & \\
\hline Stage 3 hypertension ${ }^{* * *}$ & $2(50.0)$ & $1(25.0)$ & $1(25.0)$ & - & \\
\hline
\end{tabular}

\# Pearson's chi-squared test; ${ }^{\text {\# }}$ Fisher's exact test by Monte Carlo simulation; ${ }^{*}$ Systolic arterial Pressure (SAP) $\geq 140-159$ mmHg or Diastolic arterial pressure $\geq 90-99$ mmHg;

${ }^{* *} \mathrm{SAP} \geq 160-179 \mathrm{mmHg}$ or DAP $\geq 100-109 \mathrm{mmHg} ;{ }^{* * *} \mathrm{SAP} \geq 180 \mathrm{mmHg}$ or DAP $\geq 110 \mathrm{mmHg}{ }^{[10]}$ 
Table 2 presents the gross and adjusted regressions between hypertension, adjusted for confounding factors. psychosocial stress (DCM quadrants) and systemic arterial

Table 2. Gross and adjusted associations between psychosocial stress (DCM quadrants) and systemic arterial hypertension

\begin{tabular}{|c|c|c|c|c|c|c|c|c|}
\hline \multirow{3}{*}{$\begin{array}{l}\text { Unadjusted and adjusted } \\
\text { associations }\end{array}$} & \multicolumn{8}{|c|}{ Systemic arterial hypertension } \\
\hline & \multicolumn{2}{|c|}{ Unadjusted Regression } & \multicolumn{2}{|c|}{ Model 1* } & \multicolumn{2}{|c|}{ Model $2^{* *}$} & \multicolumn{2}{|c|}{ Model $3^{* * *}$} \\
\hline & OR & CI (95\%) & OR & CI (95\%) & OR & CI (95\%) & OR & CI (95\%) \\
\hline \multicolumn{9}{|l|}{ Psychosocial Stress (DCM) } \\
\hline Low Strain & 1.00 & & 1.00 & & 1.00 & & 1.00 & \\
\hline Passive Work & 0.90 & $0.52-1.56$ & 0.75 & $0.39-1.44$ & 0.82 & $0.44-1.55$ & 0.81 & $0.43-1.53$ \\
\hline Active Work & 0.77 & $0.38-1.53$ & 1.00 & $0.54-2.52$ & 0.99 & $0.45-2.19$ & 0.88 & $0.41-1.92$ \\
\hline High Strain & 1.40 & $0.77-2.56$ & 1.18 & $0.58-2.43$ & 1.30 & $0.64-2.63$ & 1.24 & $0.63-2.47$ \\
\hline \multicolumn{9}{|l|}{ Income Per Capita } \\
\hline$>$ US 675 & & & 1.00 & & 1.00 & & 1.00 & \\
\hline$\leq$ US 675 & & & 1.57 & $0.89-2.75$ & 1.69 & $1.01-2.84$ & 1.57 & $0.94-2.61$ \\
\hline \multicolumn{9}{|l|}{ Educational Level } \\
\hline Graduate & & & 1.000 & & & & & \\
\hline Under-Graduate & & & 0.99 & $0.51-1.91$ & & & & \\
\hline \multicolumn{9}{|l|}{ Age } \\
\hline$\leq 48$ years & & & 1.00 & & 1.00 & & 1.00 & \\
\hline$\geq 49$ years & & & 2.44 & $1.43-4.17$ & 2.60 & $1.56-4.33$ & 2.45 & $1.48-4.03$ \\
\hline \multicolumn{9}{|l|}{ Skin Color (self-reported) } \\
\hline White & & & 1.00 & & 1.00 & & 1.00 & \\
\hline Other & & & 1.66 & $0.96-2.90$ & 1.76 & $1.02-3.03$ & 1.81 & 1.06-3.10 \\
\hline \multicolumn{9}{|l|}{ Work Sector } \\
\hline Emergency & & & 1.00 & & 1.00 & & & \\
\hline Surgical Center & & & 2.23 & $0.93-5.31$ & 2.08 & $0.88-4.92$ & & \\
\hline Inpatient Unit & & & 1.88 & $0.88-4.01$ & 1.71 & $0.82-3.58$ & & \\
\hline Intensive Care & & & 1.72 & $0.85-3.49$ & 1.57 & $0.79-3.12$ & & \\
\hline \multicolumn{9}{|l|}{ Job role (Nursing) } \\
\hline Nurse & & & 1.00 & & & & & \\
\hline Technician/Assistant & & & 1.46 & $0.54-3.95$ & & & & \\
\hline \multicolumn{9}{|l|}{ Time in Role } \\
\hline$\leq 15$ years & & & 1.00 & & & & & \\
\hline$>15$ years & & & 1.20 & $0.71-2.02$ & & & & \\
\hline Hosmer-Leneshow Test & 1.000 & & 0.242 & & 0.764 & & 0.939 & \\
\hline
\end{tabular}

*Adjusted regression: SAH, DCM quadrant, income per capita, educational level, age, skin color, work sector, job role, time in role;

** Adjusted regression: SAH, DCM quadrant, income per capita, age, skin color, work sector; ${ }^{* * *}$ Adjusted regression: SAH, DCM quadrant, income per capita, age, skin color.

According to the Hosmer-Leneshow Test, the third model best explains the associations found. An association was not demonstrated between SAH and psychosocial stress, however, one was found with the variables age, skin color.

\section{DISCUSSION}

The research hypothesis that work performed under high psychological demand and low control of the working activity (high strain) is positively associated to the occurrence of systemic arterial hypertension in the evaluated workers was not proven, corroborating with other studies. ${ }^{[17,18]}$ One study ${ }^{[18]}$ showed a relationship between work stress (high strain) and blood pressure in a subgroup of volunteers recently diagnosed with SAH. Similarly, there is evidence of a positive association between stress and hypertension when gender is considered. ${ }^{[14,15,19]}$

Of the 124 (32\%) nursing staff with SAH, the prevalence was higher in the passive work quadrant and similar in the low and high strain quadrants. However, the sum of the prevalence in the passive work and high strain quadrants is important $(59.7 \%)$. This data is reinforced by other studies ${ }^{[1,17,20]}$ that also found higher prevalence in these quadrants. Although the hypothesis of this study was not proven, it is worth noting that the passive work and high strain quadrants are consid- 
ered by Karasek $^{[2]}$ as having the greatest risk for causing illness, including cardiovascular conditions.

Follow-up studies, unlike studies of a cross-sectional design, have been able to demonstrate the association of stress with SAH. A meta-analysis ${ }^{[21]}$ of six cohort studies involving 34,556 volunteers, performed in order to analyze the effect of psychological stress on arterial blood pressure increase, showed that individuals with a greater reaction to stressor tasks were more likely to present an increase in arterial blood pressure when compared to those with a lower reaction (OR $=1.21 ; 95 \%$ CI: $1.14-1.28 ; p<.001)$. Although the study data showed a relatively modest magnitude of effect, the findings suggest the importance of controlling psychological stress as part of a non-drug treatment of systemic arterial hypertension.

Taking into consideration the high prevalence of SAH noted in the nursing staff involved in this study, in accordance with other Brazilian study, ${ }^{[22]}$ the importance of maintaining a constant vigilance on the health of these workers is emphasized as most presented blood pressure values corresponding to stage I SAH, often not showing signs or symptoms of the disease. Therefore, strategies should be adopted to identify health risk situations related to the work process, working environment and conditions under which work is performed.

The nursing work environment involves many stressful variables, including those related to the patient/family care and interpersonal relationships with fellow health team members. In an emergency care hospital these variables may take on greater importance when considering the clinical case of a patient (injuries and need for constant vigilance), insecurity/anxiety of the patient/family, and the need for efficient nursing staff performance. ${ }^{[23,24]}$

In this study, the lack of association between SAH and psychosocial stress may be related to interference resulting from the employment stability given to workers of public institution, could have a minimized perception of the demands arising from the work process. This aspect has also been reported in other studies involving Brazilian and foreign public institutions. ${ }^{[3,19]}$

Analysis of the nursing professionals suffering from SAH in relation to the study covariables (grouped into sociodemographic, workplace and health) showed that some variables might indicate likelihood for developing this disease. An association was seen with the variables of age, skin color and income. This finding has also been demonstrated in another study showing an SAH prevalence of $32.7 \%$ and a positive correlation with BMI, WC and age group. ${ }^{[25]}$

Age, especially older age groups, is shown to be associated with $\mathrm{SAH}$, a study investigating the biological consequences of stress found significant statistical results in relation to the age of hypertensive individuals and their relationship with the quadrants, ${ }^{[17]}$ while an alternative research showed no association between high strain and age. ${ }^{[15]}$

Another sociodemographic variable that presented a significant statistical association was income in the low strain quadrant, in which professionals with a per capita income up to US 675 were 1.69 (95\% CI: 1.01-2.84) times more likely to present $\mathrm{SAH}$ than those with a per capita income above this cutoff point. A study conducted to evaluate stress in the workplace and income found a positive association between having a lower per capita family income and the passive work and high strain quadrants. ${ }^{[6]}$

The relationship found between SAH and overweight/obesity is highlighted, the prevalence of overweight and obesity $(67 \%)$ that surpassed national indexes where the Brazilian Household Expenditure Survey from 2008 to 2009 showed a prevalence in the population for being overweight and obese of $50.1 \%$ and $12.5 \%$, respectively. These percentages are even higher when considering the southern region of Brazil (56.8\% and $15.9 \%$, respectively). ${ }^{[26]}$ Although no evident association was found following multivariate analysis, this aspect should be carefully evaluated in order to propose measures to promote worker health.

Workers with an inadequate WC are three times more likely to be classified as having $\mathrm{SAH}$, which identifies and highlights the importance of this variable for inclusion in investigations as a marker of additional risk for cardiovascular disease. ${ }^{[11]}$ White coat hypertension was unlikely as the researcher had no link with the employers or were using the garment. $^{[27]}$

The main limitations of this study is intrinsic to a crosssectional study (reverse causality bias), the observed results contribute to reinforce some findings of other studies. Given the lack of association of psychosocial stress and the occurrence of $\mathrm{SAH}$, follow-up studies are needed to elucidate more clearly the influences of the working environment on the health-illness process of workers. The findings of this study can contribute to future discussions and planning of preventive actions related to this condition, which was found to be so intense among the nursing staff of this institution.

\section{CONCLUSION}

We found a higher prevalence of hypertension, mainly corresponding to stage I, among nursing staff, associated with age, self-reported skin color referred to as non-white, and to those with an inadequate waist circumference. No association was found between hypertension and psychosocial stress. 


\section{REFERENCES}

[1] de Mello Alvesa MG, Chorb D, Faersteinc E, et al. Versão resumida da "job stress scale": adaptação para o português. Rev Saúde Pública. 2004; 38(2): 164-71.

[2] Karasek RA. Healthy work: stress, productivity, and the reconstruction of working life. Basic books; 1992.

[3] FaersteinIII E, WerneckIII GL, LopesIII CS. Estresse no trabalho e hipertensão arterial em mulheres no Estudo Pró-Saúde. Rev Saúde Pública. 2009; 43(5): 893-6. http://dx.doi.org/10.1590/S00 34-89102009000500019url

[4] Riese H, Van Doornen LJ, Houtman IL, et al. Job strain in relation to ambulatory blood pressure, heart rate, and heart rate variability among female nurses. Scandinavian journal of work, environment \& health. 2004: 477-85. http://dx.doi.org/10.5271/sjweh.8 37

[5] Alves MGdM, Chor D, Faerstein E, et al. Estresse no trabalho e hipertensão arterial em mulheres no Estudo Pró-Saúde: Estudo PróSaúde (Pro-Health Study); Estrés en el trabajo e hipertensión arterial en mujeres; Job strain and hypertension in women: Estudo Pro-Saúde (Pro-Health Study). Rev saúde pública. 2009; 43(5).

[6] Magnago TSBdS, Lisboa MTL, Griep RH, et al. Psychosocial aspects of work and musculoskeletal disorders in nursing workers. Revista latino-americana de enfermagem. 2010; 18(3): 429-35 http://dx.doi.org/10.1590/S0104-11692010000300019

[7] Kirchhof ALC, Magnago T, Camponogara S, et al. Condições de trabalho e características sócio-demográficas relacionadas à presença de distúrbios psíquicos menores em trabalhadores de enfermagem. Texto Contexto Enferm. 2009; 18(2): 215-23. http: //dx.doi.org/10.1590/S0104-07072009000200003

[8] de Souza Urbanetto J, Magalhães MCC, Maciel VO, et al. Estresse no trabalho segundo o Modelo Demanda-Controle e distúrbios psíquicos menores em trabalhadores de enfermagem. Revista da Escola de Enfermagem da USP. 2013; 47(5): 1180-6.

[9] Loures DL, Sant'Anna I, Baldotto CSdR, et al. Estresse mental e sistema cardiovascular. Arquivos brasileiros de cardiologia. 2002; 78(5): 525-30. http://dx.doi.org/10.1590/S0066-782X200 2000500012

[10] Sociedades Brasileiras de Nefrologia CeHA. Diretrizes Brasileiras de Hipertensão Arterial VI. Jornal brasileiro de nefrologia: 'orgao oficial de Sociedades Brasileira e Latino-Americana de Nefrologia. 2010; 32 (Supl. 1).

[11] Pereira M, Lunet N, Azevedo A, et al. Differences in prevalence, awareness, treatment and control of hypertension between developing and developed countries. Journal of hypertension. 2009; 27(5): $963-$ 75. http://dx.doi.org/10.1097/HJH.0b013e3283282f65

[12] Mittal BV, Singh AK. Hypertension in the developing world: challenges and opportunities. American journal of kidney diseases : the official journal of the National Kidney Foundation. 2010; 55(3): 590-8. http://dx.doi.org/10.1053/j.ajkd.2009.06.044

[13] Guimaraes Filho GC, Sousa AL, Jardim Tde S, et al. Progression of blood pressure and cardiovascular outcomes in hypertensive patients in a reference center. Arquivos brasileiros de cardiologia. 2015; 104(4): 292-8. http://dx.doi.org/10.5935/abc. 20150001

[14] Öhlin B, Berglund G, Nilsson PM, et al. Job strain, job demands and adrenergic beta1-receptor-polymorphism: a possible interaction affecting blood pressure in men. Journal of hypertension. 2008; 26(8): 1583-9. http://dx.doi.org/10.1097/HJH.0b013e328303df5 f

[15] Aboa-Éboulé C, Brisson C, Maunsell E, et al. Job strain and risk of acute recurrent coronary heart disease events. Jama. 2007; 298(14): 1652-60. http://dx.doi.org/10.1001/jama.298.14.1652

[16] Godoy-Matos A, Oliveira J, Guedes E, et al. Associação Brasileira para o Estudo da Obesidade e da Síndrome Metabólica, Diretrizes brasileiras de obesidade 2009/2010/ABESO. São Paulo: AC Farmacêutica; 2009.

[17] Fornari C, Ferrario M, Menni C, et al. Biological consequences of stress: conflicting findings on the association between job strain and blood pressure. Ergonomics. 2007; 50(11): 1717-26. http: //dx.doi.org/10.1080/00140130701674208

[18] Ducher M, Cerutti C, Chatellier G, et al. Is high job strain associated with hypertension genesis? American journal of hypertension. 2006; 19(7): 694-700. http://dx.doi.org/10.1016/j.amjhyper. 20 05.12 .016

[19] Belkic KL, Landsbergis PA, Schnall PL, et al. Is job strain a major source of cardiovascular disease risk? Scandinavian journal of work, environment \& health. 2004: 85-128. http://dx.doi .org/10.52 $71 /$ sjweh. 769

[20] Lallukka T, Lahelma E, Rahkonen O, et al. Associations of job strain and working overtime with adverse health behaviors and obesity: evidence from the Whitehall II Study, Helsinki Health Study, and the Japanese Civil Servants Study. Social science \& medicine. 2008; 66(8): 1681-98. http://dx.doi.org/10.1016/j.socsc imed. 2007.12.027

[21] Gasperin D, Netuveli G, Dias-da-Costa JS, et al. Effect of psychological stress on blood pressure increase: a meta-analysis of cohort studies. Cadernos de Saúde Pública. 2009; 25(4): 715-26. http://dx.doi.org/10.1590/S0102-311X2009000400002

[22] Custodio IL, Lima FE, Almeida MI, et al. [Sociodemographic and clinical profile of a nursing team with high blood pressure]. Rev Bras Enferm. 2011; 64(1): 18-24. http://dx.doi.org/10.1590/S00 34-71672011000100003

[23] de Melo Batista K, Bianchi ERF. Estresse do enfermeiro em unidade de emergência. Revista Latino-Americana de Enfermagem. 2006; 14(4): 534-9.

[24] Aquino EMMLL, Magalhães LBNC, Araújo MJ, et al. Hypertension in a female nursing staff-pattern of occurrence, diagnosis, and treatment. Arquivos brasileiros de cardiologia. 2001; 76(3): 203-8. http://dx.doi.org/10.1590/S0066-782X2001000300003

[25] Nascente FMN, Jardim P, Peixoto MdRG, et al. Hipertensão arterial e sua correlação com alguns fatores de risco em cidade brasileira de pequeno porte. Arquivos brasileiros de cardiologia. 2010; 95(4): 502-9. http://dx.doi.org/10.1590/S0066-782X2010005000113

[26] Estatística IBdGe. Pesquisa de Orçamentos Familiares 2008-2009. Avaliação nutricional da disponibilidade domiciliar de alimentos no Brasil. IBGE Rio de Janeiro; 2010.

[27] Cobos B, Haskard-Zolnierek K, Howard K. White coat hypertension: improving the patient-health care practitioner relationship. Psychology research and behavior management. 2015; 8: 133-41. PMID:25999772. 